\section{A case of post-inflammatory warty dyskeratoma of the chest: Other dermoscopic features}

\author{
Vito Ingordo, ${ }^{1}$ Gerardo Ferrara, ${ }^{2}$ \\ Irene Ingordo, ${ }^{3}$ Giuseppe Argenziano ${ }^{4}$ \\ ${ }^{1}$ Outpatients' Department of \\ Dermatology, District n. 6, Local Health \\ Centre Taranto, Taranto; ${ }^{2}$ Anatomic \\ Pathology Unit, Hospital of Macerata, \\ Macerata; ${ }^{3}$ Private practice, Milano; \\ ${ }^{4}$ Dermatology Unit, University of \\ Campania "L. Vanvitelli", Napoli, Italy
}

\begin{abstract}
Warty Dyskeratoma (WD) is a rare condition consisting in single or multiple papular or nodular lesions of the skin or of the oral mucosamucosa. Histologically, a cupshaped epidermal invagination centred by a plug of epidermal hyperparakeratosis with suprabasal acantholysis and dyskeratosis is typically observed. A case of post-inflammatory WD, which was also observed by dermoscopy, is described. Dermoscopy showed an eight-shape whitish collarette surrounded by light brown pigmentation. A central white structureless area with an adjacent rosette were observed. Some small rust-coloured blood crusts were also observed in the centre of the lesion; no prominent vascular pattern was detected. The etiopathogenesis of this benign neoplasm could be multifactorial. Dermoscopy of WD is not specific but may help to ruling out other skin tumors.
\end{abstract}

\section{Introduction}

After the seminal description by Helwig in 1954 as "isolated Darier's disease", ${ }^{1}$ Warty Dyskeratoma (WD) was described as a distinctive clinic-pathological entity by Szymanski in 1957. ${ }^{2}$ Shortly after, Graham and Helwig ${ }^{3}$ proposed the name "isolated dyskeratosis follicularis", because their cases exhibited a pattern of dyskeratosis and acantholysis similar to that described in Darier's disease. Ackerman ${ }^{4}$ suggested that WD should be included within the spectrum of dermatoses with Focal Acantholytic Dyskeratosis (FAD): he proposed that the term WD should be restricted to lesions clinically presenting as a single nodule, whereas papular lesions should be best labelled as "papular form of FAD". To date, however, the term WD is commonly used for both papular and nodular lesions. ${ }^{5,6}$

\section{Case Report}

A small erythemato-papular lesion superficially eroded occurred on the hairy region of the chest in a 53-year-old Caucasian man. He was on the whole in good health; he was affected by a mild hypertension which was under control with an ACE-inhibitor drug. No other skin lesions were observed. No history of Darier's disease was reported. After a oneweek topical corticosteroid-antibiotic therapy, the lesion appeared as a skin-coloured and umbilicated papule with a central keratotic plug (Figure 1A). Dermoscopy (performed with Molemax II, Derma Medical Systems, Vienna, Austria) revealed an eight-shape whitish collarette surrounded by light brown pigmentation. A central white structureless area with an adjacent rosette were observed. Some small rustcoloured blood crusts were also observed in the centre of the lesion; no prominent vascular pattern was detected (Figure 1B). Histology featured a cup-shaped epidermal invagination (Figure 1C) filled with a hyperkeratotic and parakeratotic plug, containing numerous grains and corps ronds (Figure 1D). The base of invagination consisted of hyperplastic epithelium with digitate projections (villi). Based on these microscopic features, a diagnosis of WD was made.

\section{Discussion}

Cutaneous WD is a rare condition;,56 it appears in middle-aged patients as a cutaneous elevated nodule or cyst with a raised border and a somewhat umbilicated or porelike centre. Most of the lesions are brown, but some are described as skin-coloured, yellow, red, black, tan, or grey. ${ }^{3,5,6}$ Usually a single lesion is observed, ${ }^{3,5-7}$, but cases with multiple lesions have been described. ${ }^{8-10}$ Head and neck are mainly affected. . $^{3,5-7}$ Trunk and limbs are interested in a minority of patients; $;^{3,5-7}$ a few cases of vulvar ${ }^{11}$ and oral ${ }^{12} \mathrm{WD}$ are described.

Patients affected by cutaneous WD are usually middle-aged..$^{3,5-7}$ In some case series the male sex was prevalent, ${ }^{3,7}$ in another series women were more affected than men, ${ }^{6}$ but according to other authors both sexes were interested in the same proportion. ${ }^{5}$ Mucosal WD seems instead more prevalent in middle-aged males. ${ }^{12}$

Kaddu et al. ${ }^{6}$ described three architectural patterns of cutaneous WD, namely, cup-shaped, cystic, and nodular. They hypothesized that nodular lesions may represent an early stage in the occurrence of
Correspondence: Vito Ingordo, Outpatients' Department of Dermatology, District n. 6, Local Health Centre Taranto, Taranto, 74121, Italy

Tel.: +39-099-7793821

E-mail: vito.ingordo@gmail.com

Key words: Warty dyskeratoma, dermoscopy; dermatoscopy; etiopathogenesis; histopathology.

Conflict of interest: the authors declare no potential conflict of interests.

Received for publication: 12 July 2020 . Accepted for publication: 20 July 2020.

This work is licensed under a Creative Commons Attribution-NonCommercial 4.0 International License (CC BY-NC 4.0).

CCopyright: the Author(s), 2020

Licensee PAGEPress, Italy

Dermatology Reports 2020; 12:8791

doi:10.4081/dr.2020.8791

WD, whereas cystic and cup-shaped lesions are relatively well-developed lesions. Most authors believe that cutaneous WD is derived from the hair follicle because of its closeness or clear-cut connection to pilosebaceous unit, ${ }^{3,5-7,9}$ thereby suggesting that "follicular dyskeratoma" might be a better term for this entity. ${ }^{6}$ A study performed with human keratin antibodies, specific for cortex and inner root sheet of normal human hair, ${ }^{8}$ and a survey carried out searching the expression of cytokeratins $\mathrm{CK}_{1}, \mathrm{CK}_{5}, \mathrm{Ck}_{10}$, $\mathrm{CK}_{17}, \mathrm{CK}_{19}{ }^{5}$ confirmed this hypothesis. WD arising in regions devoid of follicular structures (oral mucosa ${ }^{12}$ and nail bed ${ }^{13,14}$ ) may represent examples of isolated FAD secondary to a local inflammation or a neoplastic proliferation. 5,6,9,12 Therefore, Allon et al. suggested for oral lesions the term "isolated FAD" rather WD. ${ }^{12}$

The etiology of cutaneous WD is unknown. Ultraviolet light, autoimmunity, viral infections, and chemical carcinogens have been postulated to play a role. . $^{2,3,6,7,9,15}$ Szymanski ${ }^{2}$ showed the presence of viral DNA and RNA in the epithelial cells lining the villi, but Kaddu et al. ${ }^{6}$ failed to find HPV-DNA in wide number of HPV in their case series. In oral WD, smoking seems to play the main etiologic role. In this instance, ill-fitting dentures, alcohol use, check biting, sniff use, extraction site, and immunosuppression were also suggested how etiologic factors. ${ }^{12}$

It was proposed that WD represents a sporadic localized error in epithelial maturation and cohesiveness. ${ }^{16}$ In this regard it is interesting to emphasize that Ackerman 
classified solitary FAD in three forms: i) a clinically nonapparent type (histologically incidental lesions); ii) a papular type (focal acantholytic dyskeratoma) and iii) a nodular type (warty dyskeratoma). ${ }^{4}$ "Incidental FAD" has also been observed in many skin lesions (i.e. epithelial lesions, fibrohistiocytic lesions, inflammatory conditions, melanocytic neoplasms and miscellaneous lesions). The pathologic changes either occurred within the lesion or in the "clinically normal-appearing" epithelium immediately adjacent to the lesion ${ }^{15}$. Accordingly, as proposed by Griffiths et al. ${ }^{8}$ the development of WD at various anatomical sites could be multifactorial. This hypothesis is in agreement with the post-inflammatory onset of our case.

Clinical differential diagnosis of cutaneous and mucosal WD includes basal cell carcinoma, epidermal cyst, seborrheic keratosis, actinic keratosis, squamous cell carcinoma, melanocytic nevus, keratoacanthoma, common wart, condyloma acuminatum, bowenoid papulosis, sebaceous hyperplasia, adnexal tumour, oral papilloma or fibroma. ${ }^{5,6,11,17}$

Histological differential diagnosis must be made with Darier's disease, Grover's disease, acantholytic squamous cell carcinoma, keratoacanthoma, pemphigus vul-

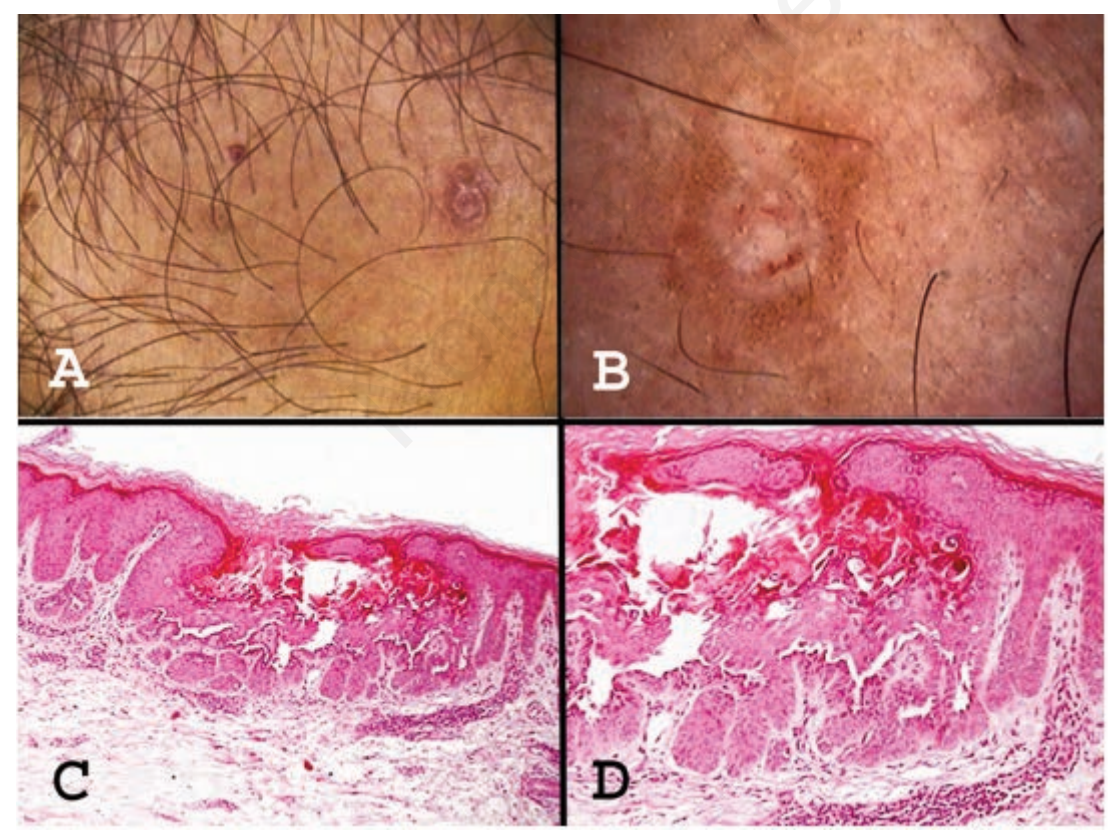

Figure 1. A) Clinical picture featuring a skin-coloured, umbilicated nodule with a central keratotic plug. B) Dermoscopy of WD, typified by an eight-shape whitish collarette surrounded by light brown pigmentation; a central white structureless area with an adjacent rosette; some small rust-coloured blood crusts at the centre of the lesion. C) Histopathologic picture disclosing a cup-shaped epidermal invagination filled with keratinous hyper-parakeratotic plug. D) A closer histologic view with numerous grains and corps ronds. garis, Hailey-Hailey disease, syringocystoadenoma papilliferum. $3,6,7,11,17$ Noteworthy, the presence of histopathologically clear surgical margins virtually excludes the inflammatory dermatoses listed above.

Dermoscopy of WD has been performed in a limited number of cases (Appendix). ${ }^{16-20}$ Papules of acantholytic dyskeratotic acanthoma, acantholytic dyskeratoses, and Grover's disease display a central yellowish to brown star-like pattern overlying a pinkish homogeneous structure-less area. ${ }^{16}$ Syringocystoadenoma papilliferum reveals a polymorphous vascular pattern on a pinkish-white background. ${ }^{19}$ Papules of Darier's disease show a centrally located yellowish/brownish area surrounded by a thin whitish halo. ${ }^{17}$ Dermoscopy of keratoacanthoma and squamous cell carcinoma is characterized by keratin masses, white structures (white circles, white clods, and white structureless areas), and hairpin vessels. ${ }^{17,20}$ In viral wart, the most frequent dermoscopic findings are the mosaic pattern and the exophytic keratotic projection pattern (dotted, linear, or hairpin vessels, often surrounded by a whitish halo), often with microhemorrages. ${ }^{20}$ 
atoma/focal acantholytic dyskeratosisan update on a rare oral lesion. J Oral Pathol Med 2012;41:261-7.

13. Baran R, Perrin C. Focal subungual warty dyskeratoma. Dermatol 1997; 195:278-80.

14. Vargas-Laguna E, Imbernón-Moya, Aguillar-Martinez A, Burgos F. An unusual location of subungual warty dyskeratoma: a case report and review of the literature. Case Rep Dermatol Med 2017;2017:3613109. doi:
$10.1155 / 2017 / 3613109$.

15. DiMaio DJ, Cohen PR. Incidental focal acantholytic dyskeratosis. J Am Acad Dermatol 1998;38:243-7.

16. Salerni G, Alonso C, Calligaris M, et al. Dermoscopy of multiple warty dyskeratoma. Dermatol Pract Concept 2017;7:47-9.

17. Nakagawa T, Umekage K, Komatsu S, et al. Case of warty dyskeratoma with unique dermoscopic features. J Dermatol 2018;45:e74-5.
18. Lencastre A, Campos S, Cabete J. Warty dyskeratoma. J Am Acad Dermatol 2016;75:e97-8.

19. Isaka Y, Matsuda H, Ogita A, et al. Case of warty dyskeratoma on the anterior chest: the relationship between its dermoscopic and histopathological findings. J Dermatol 2018;45:e171-2.

20. Di Brizzi EV, Russo T, Piccolo V, et al. Warty dyskeratomas: clinical and dermoscopic features. Int $\mathrm{J}$ Dermatol 2019;58:e229-31. 